\title{
Metastatic neuroendocrine neoplasia treatments in patients over 70 years of age
}

\author{
Alberto Bongiovanni', Federica Recine', Flavia Foca ${ }^{2}$, Valentina Fausti', Nada Riva', Greta Fabbri², \\ Stefano Severi ${ }^{3}$, Chiara Liverani ${ }^{1}$, Alessandro De Vita ${ }^{1}$, Chiara Spadazzi ${ }^{1}$, Giacomo Miserocchi ${ }^{1}$, \\ Laura Mercatali' ${ }^{1}$, Dino Amadori' ${ }^{1}$ and Toni Ibrahim ${ }^{1}$ \\ ${ }^{1}$ Osteoncology and Rare Tumors Center, Istituto Scientifico Romagnolo per lo Studio e la Cura dei Tumori (IRST) IRCCS, Meldola, Italy \\ ${ }^{2}$ Unit of Biostatistics and Clinical Trials, Istituto Scientifico Romagnolo per lo Studio e la Cura dei Tumori (IRST) IRCCS, Meldola, Italy \\ ${ }^{3}$ Nuclear Medicine Unit, Istituto Scientifico Romagnolo per lo Studio e la Cura dei Tumori (IRST) IRCCS, Meldola, Italy \\ Correspondence should be addressed to A Bongiovanni: alberto.bongiovanni@irst.emr.it
}

\begin{abstract}
The incidence of neuroendocrine neoplasia (NEN) is higher in individuals $\geq 70$ years of age (elderly) who are underrepresented in clinical trials because of comorbidities and low performance status. We retrospectively analyzed the outcome of elderly patients with metastatic NEN (mNEN). Comorbidities were summarized by Charlson Comorbidity Index (CCI), Kaplan-Meier method was applied to estimate overall survival (OS) and Cox's proportional hazard model was used to assess the impact of known prognostic factors. We retrieved data on 145 mNEN patients aged $\geq 70$ years seen at our center from June 2007 to March 2016. Fifty-six (38.6\%) were aged $\geq 75$ years. ECOG PS was 0 in $45.7 \%$ of cases and $\mathrm{CCl}$ was 0 in $41.0 \%$ and 1 in $37.4 \%$. A total of $75.4 \%$ of patients had grade (G) $1 /$ G2 NEN and 24.6\%, G3. Octreoscan/Gallium PET/CT and FDG-PET/CT were positive in $94.2 \%$ and $70.3 \%$ of cases, respectively. Median follow-up was 72.3 (53.2-85.1) months. Seventy-nine patients received first-line somatostatin analogs (SSA), 23 peptide receptor radionuclide therapy (PRRT) and 36 chemotherapy (CHT). Seven did not undergo firstline therapy and 102 received more than one line. Median overall survival (mOS) was 5.1 years $(95 \% \mathrm{Cl}: 3.4-6.6)$. No differences in mOS were seen according to $\mathrm{CCl}$. First-line PRRT patients had a mOS of 6.5 years $(95 \% \mathrm{Cl}$ : 3.3-not reached (NR)), SSA 5.7 years (95\% Cl: 4.2-7) and CHT 5.9 years (95\% Cl: 0.4-NR). mOS in CHT-treated $\mathrm{G} 3$ patients was 1.5 years (1.0-2.5). ECOG PS and FDG PET/CT were identified as independent prognostic factors. Results suggest that the above treatments positively impacted OS in elderly mNEN patients, including those aged $\geq 75$ years.
\end{abstract}

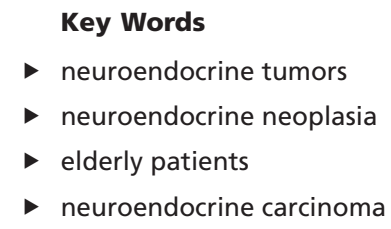

Endocrine Connections (2018) 7, 1535-1541

\section{Introduction}

Neuroendocrine neoplasia (NEN) arise from cells of the endocrine system and are a heterogeneous group of tumors originating from the embryological gut which is subdivided into the following areas: foregut (lungs, thymus, stomach and duodenum), midgut (jejunum, ileum, appendix and proximal large bowel) and hindgut (distal colon and rectum) $(1,2)$. Although the incidence of these tumors is still very low $(5.25 / 100,000 /$ year), it has increased significantly in recent years and, because of the long survival of NEN patients, prevalence is high (35/100,000/year) (3). However, recent advances in epidemiology, molecular biology, diagnostics and therapeutics are reshaping our understanding of this cancer. Demographic changes that include an ageing population may also contribute to this because the frequency of NEN increases with age (4). In particular, 
Table 1 Modified Charlson comorbidity index (mCCl).

\begin{tabular}{l} 
CCI weight \\
\hline 0 \\
1 \\
2 \\
3
\end{tabular}

\author{
Comorbid condition \\ No comorbidities \\ Myocardial infarction, congestive heart failure, peripheral vascular disease, cerebral vascular disease, dementia, \\ chronic obstructive pulmonary disease, connective tissue disease, ulcer, mild liver disease, and diabetes \\ Renal disease/kidney stones \\ Moderate or severe liver disease/cirrhosis
}

some neuroendocrine subtypes, especially gastrointestinal tumors, have a higher incidence in individuals over 70 years of age $(5,6) .40-50 \%$ of NEN patients present with distant metastases, with increasing prevalence over time depending on the initial stage of the disease. Metastases are predominantly found in the liver and/or lymph nodes. In contrast, bone metastases are reported in $<15 \%$ of cases (7). Treatment options for metastatic disease comprise liver surgery and/or locoregional and ablative therapies, somatostatin analogs, chemotherapy, targeted therapy and peptide receptor radionuclide therapy (8). Given the several treatment options, the heterogeneity of NEN and individual disease complexity, a multidisciplinary team discussion of cases, including imaging results and histology reports, is mandatory to guide treatment decision making. Although it has been seen that the primary site of the cancer strongly influences the choice of treatment, non-clinical factors such as age, sex and geographic residence should also be taken into consideration. Functional status heterogeneity in elderly patients, age-related alterations in drug metabolism and the presence of a higher number of comorbidities can affect both the expected efficacy and the adverse effects of treatments other than somatostatin analogs (SSAs). Older patients are substantially underrepresented in clinical trials because of age restrictions at study enrolment, poor performance status and the presence of comorbidities (9). In particular, there are very few data on NEN patients over the age of 80 years. For some tumors such as colorectal and breast cancer, there is evidence that the essential principles of treating advanced disease in the elderly are the same as those used for younger patients (10), and age alone should not be used to deny cancer patients from receiving potentially beneficial treatments. It is clear that, however, that greater attention must be paid to the risk of treatment toxicity and of a negative impact on the quality of life in older individuals due to age-related organ function decline and comorbidities (11). Although this large population includes a high proportion of patients who are unfit for treatment, there are also some who are in a condition to undergo monotherapy or doublets. Thus, fit older patients could also be potential candidates for clinical trials.
Given the above premises, we conducted a retrospective analysis of survival and toxicity in patients over 70 years of age treated at our institute for metastatic NEN (mNEN).

\section{Methods}

We retrospectively collected data for patients treated at our institute (IRST IRCCS) between June 2007 and March 2016. Inclusion criteria were histologically proven NEN and age $\geq 70$ years at the time of diagnosis. The following comorbidities were assessed by the Charlson Comorbidity Index (CCI) (12): myocardial infarction, congestive heart failure, peripheral vascular disease, cerebral vascular disease, dementia, chronic obstructive pulmonary disease, connective tissue disease, ulcer, mild liver disease and diabetes. One point was assigned for each of the above conditions, 2 points for moderate and severe renal disease and 3 points for moderate or severe liver disease. Other serious conditions such as hemiplegia, diabetes with organ damage, any other cancer and AIDS were not taken into account because they were considered exclusion criteria. Consequently, higher scores were rarely attained, and only four categories were used for the analysis $(0,1$, 2 and $\geq 3$ ). The modified CCI score is shown in Table 1 .

Some patients were referred to our institute by other national centers for a second opinion, while others were followed and treated at IRST from diagnosis onwards. All cases were discussed by a multidisciplinary team (MDT) comprising an oncologist, nuclear medicine physician, surgeon, radiologist, radiation oncologist, biologist and oncology nurse and a treatment plan was drawn up. ${ }^{18}$ FDG-PET positive criteria were focal area(s) of increased tracer uptake or diffusely increased uptake, excluding physiological uptake, with respect to adjacent tissue on axial, coronal and sagittal images. Octreoscan $/{ }^{68} \mathrm{GaPET} /$ CT positivity is based on a greater intensity than that of the background uptake and that cannot be considered as physiologic activity (pituitary gland, spleen, liver, adrenal glands, head of the pancreas, thyroid and urinary tract).

All the pathology reports were revised by an expert pathologist using the most recent version of the WHO

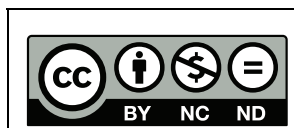

This work is licensed under a Creative Commons Attribution-NonCommercial-NoDerivatives 4.0 International License. 
classification for each primary tumor site, i.e. WHO 2010 version for gastrointestinal NENs and WHO for 2017 pancreatic NENs $(13,14)$. Conversely, Pelosi et al.'s proposed classification used for lung NENs (15).

The study was approved by the Ethical Committee of IRST IRCCS and consent was obtained from each patient or subject after full explanation of the purpose and nature of all procedures used.

\section{Statistical analysis}

Categorical variables are presented as numbers and percentages. Continuous variables are presented using median and range. Overall survival (OS) was defined as the time from the date of diagnosis to the date of death. Event-free patients were censored on the date of their last follow-up. OS is reported as a median value expressed in years, with 95\% CIs. Survival curves were estimated using the Kaplan-Meier product-limit method. The role of stratification factor was analyzed with the log-rank test. We used the Cox proportional hazards regression model to estimate hazard ratios (HRs) and relative 95\% CI of potential clinical prognostic factors for OS. Important variables such as gender were included in multivariate analysis, even when univariate analysis did not identify them as significant. All tests were two-tailed and $P$ values $<0.05$ were considered statistically significant. No adjustments were made for multiple comparisons. Statistical analyses were carried out with STATA/MP 14.0 for Windows (StataCorp LLP, College Station, TX, USA).

\section{Results}

We identified 145 patients (86 male/59 female) $\geq 70$ years treated for mNEN at our institute during the study period. Median age was 74 years (range 70-87 years). Fifty-six (38.6\%) patients were $\geq 75$ years. Eastern Cooperative
Oncology Group Performance Status (ECOG PS) was 0 in $45.7 \%, 1$ in $46.5 \%$ and $\geq 2$ in $7.8 \%$ of cases. Fifty-seven $(41.0 \%)$ patients had a CCI score of $0,52(37.4 \%)$ a score of $1,19(13.7 \%)$ a score of 2 and $11(7.9 \%)$ a score of $\geq 3$. This information was not available in $4 \%$ of patients. Hepatic or extra-hepatic metastases were identified in $58(40.0 \%)$ and 29 (20.0\%) of cases, respectively. Ninety-five (75.4\%) patients had grade (G)1/G2 NEN and 31 (24.6\%) G3 NEN. Gallium/Octreoscan and fluorodeoxyglucose (FDG) PET/CT scans were positive in 130/138 (94.2\%) and 76/108 (70.3\%) patients, respectively. Radiological and/or imaging tests were performed in 138 (95.2\%) cases to evaluate the disease. Forty-two (29.4\%) patients had functioning tumors of which 4 were insulinoma, 1 gastrinoma and 37 carcinoid syndrome. Patient's characteristics are summarized in Table 2. First-line treatments were somatostatin analogs (SSAs) in 79 (54.5\%) patients, peptide receptor radionuclide therapy (PRRT) in 23 (15.9\%) and chemotherapy in 36 (24.8\%). Seven (4.8\%) patients did not undergo first-line treatment because of poor clinical conditions (Fig. 1). Interventional radiological treatments (transarterial embolization or radiofrequency ablation) were performed in eight cases. Among those who received first-line therapy, 102 (73.9\%) underwent more than one line. Two patients received everolimus as secondline therapy after SSA and one third-line everolimus after SSA and PRRT. One hundred and twenty-five patients with assessment of vital status were considered for OS analysis. Median follow-up was 72.3 months (range 1-225 months) and median OS was 5.1 years (95\% CI: 3.4-6.6).

ECOG PS and FDG PET/CT results assessed by a multivariate Cox regression model were confirmed as independent prognostic factors for OS, with a higher risk for patients with ECOG PS >0 (HR 3.48 (95\% CI: 1.50-8.06)) and a positive FDG PET/CT (HR 2.90 (95\% CI: 1.12-7.52)). Age at diagnosis showed a hazard ratio of 1.11 (95\% CI: 0.99-1.26) (Table 3). Sixty-eight patients died during the study period, 39 from cancer and 1 from acute myocardial

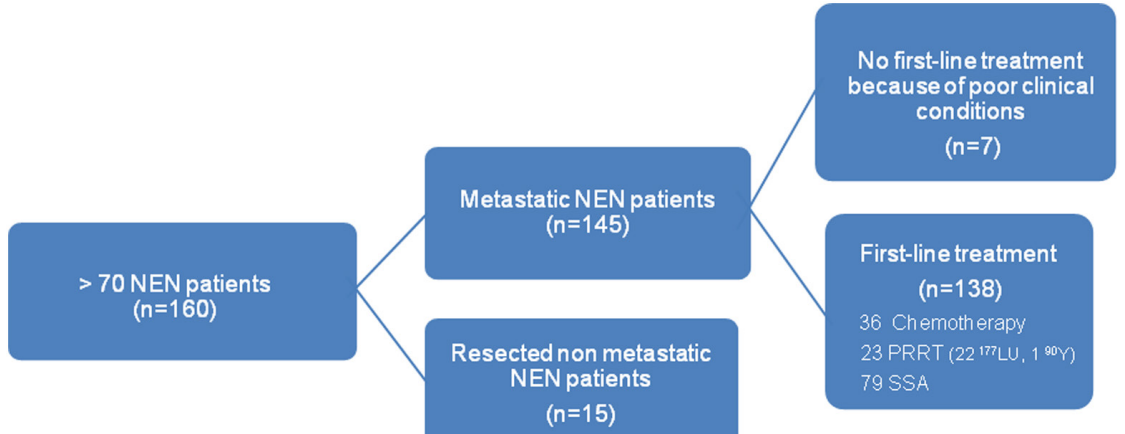

https://ec.bioscientifica.com https://doi.org/10.1530/EC-18-0478 (c) 2018 The authors Published by Bioscientifica Ltd

\section{Figure 1}

Flow chart of patient selection. NEN, neuroendocrine neoplasm; PRRT, peptide receptor radionuclide therapy; ${ }^{177} \mathrm{LU},{ }^{177}$ Lutetium-Dotatate; ${ }^{90}$ Y, ${ }^{90}$ Yttrium-Dotatoc; SSA, somatostatin analog. 
Table 2 Patient characteristics.

\begin{tabular}{|c|c|}
\hline Patient characteristics & $\boldsymbol{N}(\%)$ \\
\hline \multicolumn{2}{|l|}{ Gender } \\
\hline Male & $86(59.3)$ \\
\hline Female & $59(40.7)$ \\
\hline Median age at diagnosis (years) (range) & $74(70-87)$ \\
\hline \multicolumn{2}{|l|}{ ECOG performance status } \\
\hline ECOG 0 & 59 (45.7) \\
\hline ECOG 1 & $60(46.5)$ \\
\hline$E C O G \geq 2$ & $10(7.8)$ \\
\hline Unknown & 16 \\
\hline \multicolumn{2}{|l|}{ Charlson comorbidity index } \\
\hline 0 & $57(41.0)$ \\
\hline 1 & $52(37.4)$ \\
\hline 2 & 19 (13.7) \\
\hline$\geq 3$ & $11(7.9)$ \\
\hline Unknown & 6 \\
\hline \multicolumn{2}{|l|}{ Functioning tumors } \\
\hline Yes & 42 (29.4) \\
\hline $\mathrm{N}$ & $101(70.6)$ \\
\hline Unknown & 2 \\
\hline \multicolumn{2}{|l|}{ Site of disease } \\
\hline Gastro-entero-pancreatic & $74(51.0)$ \\
\hline Lung & $32(22.1)$ \\
\hline Other* & $10(6.9)$ \\
\hline Unknown & 29 \\
\hline \multicolumn{2}{|l|}{ Grading } \\
\hline G1 & $33(26.2)$ \\
\hline $\mathrm{G} 2$ & $62(49.2)$ \\
\hline G3 & $31(24.6)$ \\
\hline Unknown & 19 \\
\hline \multicolumn{2}{|l|}{ Previous surgery } \\
\hline Yes & $80(55.9)$ \\
\hline No & $63(44.1)$ \\
\hline Unknown & 2 \\
\hline \multicolumn{2}{|l|}{ Metastatic sites } \\
\hline Hepatic & $58(40.0)$ \\
\hline Extrahepatic & $29(20.0)$ \\
\hline Hepatic+extrahepatic & $58(40.0)$ \\
\hline \multicolumn{2}{|l|}{$\mathrm{PET} / \mathrm{CT}$} \\
\hline Octreoscan & $35(25)$ \\
\hline Gallium & $93(65.0)$ \\
\hline Gallium + Octreoscan & $10(7.0)$ \\
\hline Not performed & $4(3)$ \\
\hline Unknown & 3 \\
\hline Patients positive to Octreoscan/Gallium PET/CT & $130(94.2)$ \\
\hline Patients positive to FDG PET & $76(70.3)$ \\
\hline \multicolumn{2}{|l|}{ Ki67 } \\
\hline$\leq 20$ & 78 (79.6) \\
\hline$>20$ & $20(20.4)$ \\
\hline Unknown & 47 \\
\hline
\end{tabular}

ECOG, Eastern Cooperative Oncology Group; FDG, fluorodeoxyglucose. *2 cases of neuroendocrine neoplasia of the gynecologic tract; 4 cases of gallbladder as primary tumor; one case of parotid gland neuroendocrine tumor; 2 cases of atypical laryngeal carcinoid tumor; one case of atypical rhinopharyngeal carcinoid tumor.

ischemia unrelated to any antineoplastic treatment; data on the remaining 28 patients were not available. No difference in OS curves were seen on the basis of CCI $(P=0.1014)$ or age $<75$ and $\geq 75$ years $(P=0.6408)$.

\section{Somatostatin analog treatment}

Long-acting octreotide $20 \mathrm{mg}$ every 4 weeks was administered in 10 patients, while 43 received a dose of $30 \mathrm{mg}$ every 4 weeks. Lanreotide $120 \mathrm{mg}$ every 4 weeks was administered in 26 patients. Treatment was very well tolerated, with only one case each of G1, G2 and G3 diarrhea recorded. G1 cholelithiasis was registered in three cases. Median OS was 5.7 years (95\% CI: 4.2-7.0) in G1-G2 NEN patients.

\section{Peptide radioreceptor therapy}

Twenty-two patients received ${ }^{177}$ Lutetium-Dotatate therapy and only one underwent ${ }^{90}$ Yttrium-Dotatoc therapy in a first-line setting. The following toxicities were recorded: two cases of neutropenia G1, one case of G1 anemia, one case of G3 pancytopenia and three cases of thrombocytopenia G1. One patient developed a myelodysplastic syndrome. Non-hematological toxicities were G2 elevated creatinine (one patient), G1 diarrhea (one) and G1 nausea/vomiting (one). G1-G2 NEN patients who underwent first-line PRRT had a median OS of 6.5 years (95\% CI: 3.3-NR). The median OS for patients with Ki67 >20\% was 3.2 years in those treated with PRRT and 1.5 years in those who received chemotherapy.

\section{Chemotherapy}

Several chemotherapy regimens were used according to tumor differentiation. Patients with G3 NEC received platinum-based chemotherapy. In particular, 12 (67\%) received carboplatin and 6 (33\%) cisplatin, both associated with etoposide. Three patients underwent monotherapy with cisplatin, two with carboplatin and two with etoposide. For G1/2 NET, two patients received FOLFOX (folinic acid, 5-fluorouracil and oxaliplatin)/ XELOX (oxaliplatin and capecitabine) and 2, the CAPTEM (capecitabine and temozolomide) regimen. Three patients received temozolomide and four, capecitabine of whom two with a metronomic schedule. Hematological toxicity was as follows: G1/G2 anemia (3 cases); G3/G4 neutropenia G3/G4 (6 cases); G2 thrombocytopenia (one case) and G2 thrombocytopenia (2 cases). G2 nausea and vomiting were recorded in four patients and G1/G2 diarrhea in four patients. G1-G2 NEN patients pretreated with firstline chemotherapy had a median OS of 5.9 years (95\% CI: 0.4-NR). G3 NEN patients who underwent chemotherapy had a median OS of 1.5 years (1.0-2.5). Survival data are summarized in Table 3.

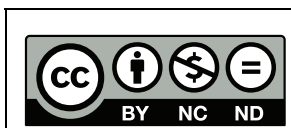
This work is licensed under a Creative Commons
Attribution-NonCommercial-NoDerivatives 4.0 International License. 
Table 3 Univariate and multivariate model for overall survival.

\begin{tabular}{|c|c|}
\hline Variables & No. cases \\
\hline Age at diagnosis & 125 \\
\hline ECOG (>0 vs 0$)$ & 109 \\
\hline Surgery (yes vs no) & 124 \\
\hline $\begin{array}{l}\text { FDG PET (positive vs } \\
\text { negative) }\end{array}$ & 89 \\
\hline $\begin{array}{l}\text { Grading and first-line } \\
\text { treatment }\end{array}$ & 94 \\
\hline $\begin{array}{l}\text { G1/G2 + PRRT vs } \\
\text { G1/G2 + SSA }\end{array}$ & \\
\hline $\begin{array}{l}\mathrm{G} 1 / \mathrm{G} 2+\mathrm{CHT} \text { vs } \\
\mathrm{G} 1 / \mathrm{G} 2+\mathrm{SSA}\end{array}$ & \\
\hline $\mathrm{G} 3+\mathrm{CHT}$ vs $\mathrm{G} 1 / \mathrm{G} 2+\mathrm{SSA}$ & \\
\hline
\end{tabular}

\begin{tabular}{c}
\hline Hazard ratio \\
\hline 1.10 \\
2.10 \\
0.42 \\
3.84
\end{tabular}

\begin{tabular}{crr} 
Univariate model & \\
\hline $95 \% \mathrm{Cl}$ & & $P$ Value \\
\hline $1.03-1.17$ & & 0.002 \\
$1.17-3.75$ & & 0.012 \\
$0.25-0.71$ & & 0.001 \\
$1.84-8.03$ & & $<0.001$
\end{tabular}

\begin{tabular}{|c|c|c|}
\hline \multicolumn{3}{|c|}{ Multivariate model } \\
\hline Hazard ratio & $95 \% \mathrm{Cl}$ & $P$ Value \\
\hline 1.11 & $0.99-1.26$ & 0.051 \\
\hline 3.48 & $1.50-8.06$ & 0.003 \\
\hline 0.74 & $0.30-1.81$ & 0.513 \\
\hline 2.90 & $1.12-7.52$ & 0.028 \\
\hline
\end{tabular}

95\% Cl, 95\% confidence interval; $\mathrm{CHT}$, chemotherapy; ECOG, Eastern Cooperative Oncology Group; FDG PET, 18-fludeoxyglucose positron emission tomography; PRRT, peptide receptor radionuclide therapy; SSA, somatostatin analog.

\section{Discussion}

Older patients with metastatic cancer are generally undertreated with respect to younger patients because of comorbidities and low performance status. Less is known about the former group because patients over 70 years of age are generally excluded from randomized clinical trials $(10,12)$. However, information obtained from clinical studies may not apply to elderly patients because treatment benefits and side effects, as well as life expectancy, differ from those of their younger counterparts (16). For these reasons, little information is available on prognosis and on the risks of treatment in this subgroup, especially for those with NEN. There is no doubt that widespread prejudice about life expectancy is currently preventing cancer specialists from offering the best possible treatments to senior adults. This seems grossly unfair as, for example, in the United States, it is estimated that the average 75-year-old male in good health has another 18 years of life ahead, decreasing to 10 years at the age of 82 (17). Older patients with mNEN are generally treated (surgery, chemotherapy or radiotherapy) less frequently than their younger counterparts and many do not receive what is considered as the standard approach. Consequently, limited data are available on the risks and benefits of specific anticancer therapies in the elderly (12). Conversely, our retrospective analysis suggests that NEN patients well past their 70s or even with comorbidities can benefit from specific treatments. In our case series, median OS survival after first-line PPRT treatment was 6.5 years (3.3-NR), 5.7 (range $4.2-7$ ) years for the SSA group and 5.9 (range 0.4-NR) years for those receiving chemotherapy. This outcome is similar to that reported for younger patients by other authors $(18,19)$.
In their study of patients with advanced neuroendocrine carcinoma (NEC), Sorbye et al. (20) reported a median OS of 5.8 months for PRRT patients and 13.5 months for those given chemotherapy. The choice of treatment was based on the different aggressiveness of the disease: chemotherapy was used in poorly differentiated tumors and PRRT in more highly differentiated tumors showing Gallium PET/CT positivity. Our findings suggest a possible role of first-line PRRT in G3 NEC patients whose tumors have more differentiated features (also known as pancreatic G3 NET according to the new classification) (21). Further prospective clinical studies are needed in this patient setting. Age and comorbidities did not worsen outcome in our case series, perhaps because of the good tolerability to the specific treatments administered. However, FDG PET and PS ECOG remained independent prognostic factors. Our study, the first to provide an overview of the clinical characteristics and outcome of elderly patients with NEN, suggests that a key issue in this patient setting is the difference between chronological and biological age. However, some limitations are present, for example, formal geriatric assessment was not performed. We believe that the routine use of a validated tool to evaluate functional, mental and clinical status would substantially facilitate the selection of patients who could potentially benefit from treatment and help to identify the most suitable therapeutic option. In addition, the retrospective nature of our study did not permit us to perform an accurate analysis of the side effects of the different treatments. There was also a selection bias because we chose patients for the study with the best clinical conditions who were physically able to undergo different treatments and, if necessary, travel to our institute from another hospital. Such patients, consequently, had a better outcome.

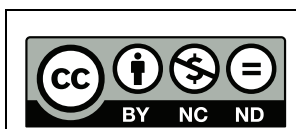

This work is licensed under a Creative Commons Attribution-NonCommercial-NoDerivatives 4.0 International License. 
In conclusion, the results from the present study suggest that treatment had a positive effect on the overall survival of elderly NEN patients, independently of age. Thus, although more clinical trials dedicated to elderly patients are warranted, there would seem to be potential for offering suitable patients from this population, identified using selection criteria including FDG PET/CT and ECOG PS, the same standard of care used for younger patients.

\section{Declaration of interest}

The authors declare that there is no conflict of interest that could be perceived as prejudicing the impartiality of the research reported.

\section{Funding}

This research did not receive any specific grant from funding agencies in the public, commercial, or not-for-profit sectors.

\section{Author contribution statement}

Alberto Bongiovanni and Toni Ibrahim conceived the idea for the study. Chiara Liverani, Chiara Spadazzi and Laura Mercatali performed the literature search and advised on the clinical classification of NENs and $\mathrm{CCI}$ score. Alessandro De Vita, Giacomo Miserocchi, Valentina Fausti and Greta Fabbri were responsible for data collection. Stefano Severi and Nada Riva interpreted the clinical data on response to therapy. Flavia Foca performed the statistical analyses. Alberto Bongiovanni, Federica Recine and Toni Ibrahim drafted the manuscript. Dino Amadori and Toni Ibrahim critically reviewed the manuscript for important intellectual content. All authors read and approved the final version of the paper.

\section{Acknowledgements}

The authors thank Cristiano Verna and Gráinne Tierney for editorial assistance.

\section{References}

1 Modlin IM, Moss SF, Chung DC, Jensen RT \& Snyderwine E. Priorities for improving the management of gastroenteropancreatic neuroendocrine tumors. Journal of the National Cancer Institute 2008 100 1282-1289. (https://doi.org/10.1093/jnci/djn275)

2 Kulke MH, Shah MH, Benson AB 3rd, Bergsland E, Berlin JD, Blaszkowsky LS, Emerson L, Engstrom PF, Fanta P, Giordano T, et al. Neuroendocrine tumors, version 1. 2015. Journal of the National Comprehensive Cancer Network 201513 78-108. (https://doi. org/10.6004/jnccn.2015.0011)

3 Yao JC, Hassan M, Phan A, Dagohoy C, Leary C, Mares JE, Abdalla EK, Fleming JB, Vauthey JN, Rashid, et al. One hundred years after 'carcinoid': epidemiology of and prognostic factors for neuroendocrine tumors in 35,825 cases in the United States. Journal of Clinical Oncology 200826 3063-3072. (https://doi.org/10.1200/ JCO.2007.15.4377)

4 Fraenkel M, Kim M, Faggiano A, de Herder WW, Valk GD \& Knowledge NETWork. Incidence of gastroenteropancreatic neuroendocrine tumours: a systematic review of the literature. Endocrine-Related Cancer 201421 R153-R163. (https://doi. org/10.1530/ERC-13-0125)
5 Halfdanarson TR, Rubin J, Farnell MB, Grant CS \& Petersen GM. Pancreatic endocrine neoplasms: epidemiology and prognosis of pancreatic endocrine tumors. Endocrine-Related Cancer 200815 409-427. (https://doi.org/10.1677/ERC-07-0221)

6 Lawrence B, Gustafsson B, Chan A, Svejda B, Kidd M \& Modlin IM. The epidemiology of gastroenteropancreatic neuroendocrine tumors. Endocrinology and Metabolism Clinics of North America 201140 1-18. (https://doi.org/10.1016/j.ecl.2010.12.005)

7 Oberg K \& Eriksson B. Endocrine tumours of the pancreas. Best Practice and Research Clinical Gastroenterology 200519 753-781.

8 Pavel M, O’Toole D, Costa F, Capdevila J, Gross D, Kianmanesh R, Krenning E, Knigge U, Salazar R, Pape UF, et al. ENETS Consensus Guidelines update for the management of distant metastatic disease of intestinal, pancreatic, bronchial neuroendocrine neoplasms (NEN) and NEN of unknown primary site. Neuroendocrinology $2016 \mathbf{1 0 3}$ 172-185. (https://doi.org/10.1159/000443167)

9 Sehl M, Sawhney R \& Naeim A. Physiologic aspects of aging: impact on cancer management and decision making, part II. Cancer Journal 200511 461-473. (https://doi.org/10.1097/00130404-20051100000005)

10 Zulman DM, Sussman JB, Chen X, Cigolle CT, Blaum CS \& Hayward RA. Examining the evidence: a systematic review of the inclusion and analysis of older adults in randomized controlled trials. Journal of General Internal Medicine 201126 783-790. (https:// doi.org/10.1007/s11606-010-1629-x)

11 Golfinopoulos V, Pentheroudakis G \& Pavlidis N. Treatment of colorectal cancer in the elderly: a review of the literature. Cancer Treatment Reviews 200632 1-8. (https://doi.org/10.1016/j. ctrv.2005.10.002)

12 Hutchins LF, Unger JM, Crowley JJ, Coltman A \& Albain KS. Under representation of patients 65 years of age or older in cancer treatment trials. New England Journal of Medicine 1999341 2061-2067. (https://doi.org/10.1056/NEJM199912303412706)

13 Araujo PB, Cheng S, Mete O, Serra S, Morin E, Asa SL \& Ezzat S. Evaluation of the WHO 2010 grading and AJCC/UICC staging systems in prognostic behavior of intestinal neuroendocrine tumors. PLoS ONE 20138 e61538. (https://doi.org/10.1371/journal. pone.0061538)

14 Amin MB, Edge S, Greene F, Byrd DR, Brookland RK, Washington MK, Gershenwald JE, Compton CC, Hess KR, Sullivan DC, et al. AJCC Cancer Staging Manual, 8th ed. Berlin, Germany: Springer, 2017.

15 Pelosi G, Pattini L, Morana G, Fabbri A, Faccinetto A, Fazio N, Valeri B \& Sonzogni A. Grading lung neuroendocrine tumors: controversies in search of a solution. Histology and Histopathology 201732 223-241. (https://doi.org/10.14670/HH-11-822)

16 Rutten HJ, den Dulk M, Lemmens VE, van de Velde CJ \& Marijnen CA. Controversies of total mesorectal excision for rectal cancer in elderly patients. Lancet Oncology 20089 494-501. (https:// doi.org/10.1016/S1470-2045(08)70129-3)

17 Walter LC \& Covinsky KE. Cancer screening in elderly patients: a framework for individualized decision making. JAMA 2001285 2750-2756. (https://doi.org/10.1001/jama.285.21.2750)

18 Genc CG, Klümpen HJ, van Oijen MGH, van Eijck CHJ \& Nieveen van Dijkum EJM. A nationwide population-based study on the survival of patients with pancreatic neuroendocrine tumors in the Netherlands. World Journal of Surgery $2018 \mathbf{4 2}$ 490-497. (https://doi. org/10.1007/s00268-017-4278-y)

19 Boyar Cetinkaya R, Aagnes B, Myklebust TÅ \& Thiis-Evensen E. Survival in neuroendocrine neoplasms; a report from a large Norwegian population-based study. International Journal of Cancer 2018142 1139-1147. (https://doi.org/10.1002/ijc.31137)

20 Sorbye H, Welin S, Langer SW, Vestermark LW, Holt N, Osterlund P, Dueland S, Hofsli E, Guren MG, Ohrling K, et al. Predictive and prognostic factors for treatment and survival in 305 patients with advanced Gastrointestinal neuroendocrine carcinoma (WHO G3): 
the NORDIC NEC study. Annals of Oncology. 201324 152-160. (https://doi.org/10.1093/annonc/mds276)

21 Perren A, Couvelard A, Scoazec JY, Costa F, Borbath I, Delle Fave G, Gorbounova V, Gross D, Grossma A, Jense RT, et al.
ENETS Consensus Guidelines for the standards of care in neuroendocrine tumors: pathology: diagnosis and prognostic stratification. Neuroendocrinology 2017105 196-200. (https://doi. org/10.1159/000457956)

Received in final form 3 December 2018

Accepted 7 December 2018

Accepted Preprint published online 7 December 2018
This work is licensed under a Creative Commons Attribution-NonCommercial-NoDerivatives 4.0 International License. 